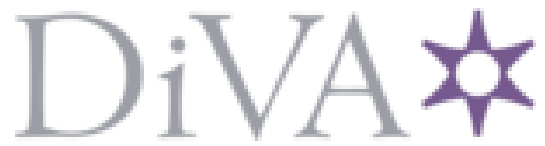

http://www.diva-portal.org

This is the published version of a paper published in Ecosystems (New York. Print).

Citation for the original published paper (version of record):

Sitters, J., te Beest, M., Cherif, M., Giesler, R., Olofsson, J. (2017)

Interactive Effects Between Reindeer and Habitat Fertility Drive Soil Nutrient Availabilities in Arctic Tundra.

Ecosystems (New York. Print), 20(7): 1266-1277

https://doi.org/10.1007/s10021-017-0108-1

Access to the published version may require subscription.

N.B. When citing this work, cite the original published paper.

This article is distributed under the terms of the Creative Commons Attribution 4.0 International License (http://creativecommons.org/licenses/by/4.o/)

Permanent link to this version:

http://urn.kb.se/resolve?urn=urn:nbn:se:umu:diva-135470 


\title{
Interactive Effects Between Reindeer and Habitat Fertility Drive Soil Nutrient Availabilities in Arctic Tundra
}

\author{
Judith Sitters, ${ }^{1,2 *}$ Mariska te Beest, ${ }^{1}$ Mehdi Cherif, ${ }^{1}$ Reiner Giesler, ${ }^{1,3}$ and \\ Johan Olofsson ${ }^{1}$
}

\begin{abstract}
${ }^{1}$ Department of Ecology and Environmental Science, Umea University, 90187 Umeå, Sweden; ${ }^{2}$ Ecology and Biodiversity, Department Biology, Vrije Universiteit Brussel, 1050 Brussels, Belgium; ${ }^{3}$ Climate Impacts Research Centre, Department of Ecology and Environmental Science, Umea University, 98701 Abisko, Sweden
\end{abstract}

\begin{abstract}
Herbivores impact nutrient availability and cycling, and the net effect of herbivory on soil nutrients is generally assumed to be positive in nutrient-rich environments and negative in nutrient-poor ones. This is, however, far from a uniform pattern, and there is a recognized need to investigate any interactive effects of herbivory and habitat fertility (i.e., plant $\mathrm{C} / \mathrm{N}$ ratios) on soil nutrient availabilities. We determined long-term effects of reindeer on soil extractable nitrogen $(\mathrm{N})$ and phosphorus $(\mathrm{P})$ and their net mineralization rates along a fertility gradient of plant carbon (C) to $\mathrm{N}$ and $\mathrm{P}$ ratios in arctic tundra. Our results showed that reindeer had a positive effect on soil $\mathrm{N}$ in the more nutrient-poor sites and a negative effect on soil P in the more nutrient-rich sites, which contrasts from the general consensus. The increase in $\mathrm{N}$ availability was linked to a decrease in plant and litter $\mathrm{C} / \mathrm{N}$ ratios,
\end{abstract}

suggesting that a shift in vegetation composition toward more graminoids favors higher $\mathrm{N}$ cycling. Soil $\mathrm{P}$ availability was not as closely linked to the vegetation and is likely regulated more by herbivore-induced changes in soil physical and chemical properties. The changes in soil extractable $\mathrm{N}$ and $\mathrm{P}$ resulted in higher soil N/P ratios, suggesting that reindeer could drive the vegetation toward P-limitation. This research highlights the importance of including both the elements $\mathrm{N}$ and $\mathrm{P}$ and conducting studies along environmental gradients in order to better understand the interactive effects of herbivory and habitat fertility on nutrient cycling and primary production.

Key words: carbon; decomposition; grazing; herbivory; litter; microbial mineralization; nitrogen; nutrient cycling; phosphorus; plant stoichiometry.
Received 30 September 2016; accepted 4 December 2016; published online 1 February 2017

Electronic supplementary material: The online version of this article (doi:10.1007/s10021-017-0108-1) contains supplementary material, which is available to authorized users.

Author contributions JS contributed to design of the study, performed research, analysed data, and wrote the paper. MB contributed to design of the study, research and writing of the paper. MC, RG, JO contributed to design of the study and writing of the paper.

*Corresponding author; e-mail: judith.sitters@vub.ac.be

\section{INTRODUCTION}

Large mammalian herbivores influence nutrient cycling in ecosystems throughout the world (Milchunas and Lauenroth 1993; Hobbs 1996; Bardgett and Wardle 2003). The main mechanism by which they do this is by changing the quantity and/or quality of resources supplied to the soil, affecting the rate of organic matter decomposition and soil nutrient availability (McNaughton 1984; 
Wilsey and others 1997; Bardgett and Wardle 2003; Pastor and others 2006). Herbivores influence the rate and form of nutrients that are returned to the soil directly by returning nutrients consumed as plant material in the form of dung and urine or indirectly by altering plant litter quantity and its nutrient content and degradability (McNaughton and others 1997; Ritchie and others 1998; Bardgett and Wardle 2003; Bakker and others 2009). These mechanisms occur simultaneously and can have contrasting effects on soil nutrient availability and hence primary production. For instance, empirical studies have found positive (Hobbs and others 1991; Frank and Evans 1997; McNaughton and others 1997), negative (Pastor and others 1993; Ritchie and others 1998; Fornara and Du Toit 2008) or mixed effects (Olofsson and others 2001; Olofsson and Oksanen 2002; Stark and Grellmann 2002; Stark and others 2003) of herbivores on nitrogen (N) cycling and primary production.

One factor that might explain these mixed effects of herbivores on nutrient cycling is the initial nutrient availability in a system. Traditionally it has been assumed that herbivores have mainly positive effects on $\mathrm{N}$ availability and primary production in nutrient-rich environments dominated by plants of high quality (i.e., low carbon (C) to $\mathrm{N}$ ratios), and mainly negative ones in nutrient-poor environments dominated by plants of low quality (i.e., high $\mathrm{C} / \mathrm{N}$ ratios) (Hobbs 1996; Bardgett and Wardle 2003; Pastor and others 2006). This is based on the facts that (1) herbivores excrete a higher proportion of nutrients consumed when the nutrient content of plants is higher (Hobbs 1996), and (2) herbivory favors resilient plants with high litter quality in nutrient-rich environments and resistant plants with low litter quality in nutrient-poor environments (Bardgett and Wardle 2003). However, this is far from a uniform pattern and at least one study has actually supported the opposite pattern, that is, a negative relationship between habitat/plant quality and the effect of herbivores on $\mathrm{N}$ availability (Bakker and others 2009). Proposed explanations for these contradictory results include the importance of other factors than initial nutrient availability in determining the net effect of herbivores on soil $\mathrm{N}$, such as trampling-induced soil compaction or lateral transport of nutrients between habitats (Sitters and Olde Venterink 2015). In addition, a recent model analysis predicts that herbivory will decrease microbial activity by reducing $\mathrm{C}$ supply to the soil through consumption of plant biomass and will thus have a negative effect on $\mathrm{N}$ availability at low plant $\mathrm{C} / \mathrm{N}$ ratios through a decrease in mineralization rates and a positive effect at higher plant $\mathrm{C} / \mathrm{N}$ ratios through a decrease in immobilization rates (Cherif and Loreau 2013). These studies emphasize the need to investigate the effects of herbivores across environmental gradients.

We conducted our study in a reindeer-grazed tundra system in northern Fennoscandia. For two reasons this is a suitable system to test the effects of herbivory on nutrient availability across a productivity gradient: (1) plant community structure and stoichiometry is known to vary dramatically along topographic gradients at relatively small spatial scales (Björk and others 2007; Chu and Grogan 2010; Sundqvist and others 201la), and (2) reindeer have been shown to have strong but varying effects on nutrient availability (Olofsson and others 2001; Stark and Grellmann 2002; Stark and others 2002; Olofsson and others 2004; Van der Wal and Brooker 2004; Stark and others 2010). So far, studies on the effects of reindeer on nutrient availability have focused primarily on $\mathrm{N}$, likely because it is considered to be the main limiting nutrient in tundra ecosystems (Shaver and Chapin 1980; Tamm 1991; Aerts and Chapin 2000). However, recent studies suggest that phosphorus (P) might be more important for plant productivity than previously assumed (Giesler and others 2012; Sundqvist and others 2014) and so the effect of herbivores on soil $\mathrm{P}$ availability warrants our attention.

The aim of this study is therefore to determine the long-term effects of reindeer on soil $\mathrm{N}$ and $\mathrm{P}$ availabilities and plant nutrient traits across a topographic gradient encompassing both nutrientpoor and nutrient-rich environments. More specifically, we test the hypotheses that herbivory will have a negative effect on $\mathrm{N}$ and $\mathrm{P}$ availabilities in nutrient-rich environments and a positive effect in nutrient-poor environments.

\section{Material And Methods}

\section{Study Area}

The study area is located in Reisadalen, Troms Fylke, northern Norway $\left(69^{\circ} 30^{\prime} \mathrm{N}, 27^{\circ} 30^{\prime} \mathrm{E}\right)$ between 500 and $700 \mathrm{~m}$ a.s.l., which is about $100 \mathrm{~m}$ above the local tree line. The area experiences a sub-oceanic climate (Oksanen and Virtanen 1995). Mean annual temperature at the site was $-3.3^{\circ} \mathrm{C}$ based on local loggers, and the average precipitation at the nearest climatic station (Kautokeino) is $389 \mathrm{~mm} /$ year. We conducted the study across a reindeer fence, established in the 1960s to prevent reindeer from entering their winter ranges during 
summer. The fence runs for several kilometers across the tundra and divides it into a side that is only very lightly grazed and a side that is heavily grazed (Olofsson and others 2001; see Appendix A for measures of reindeer activity). There is thus no difference in the timing of the presence of reindeer among the grazing regimes, only a large difference in reindeer density. We want to emphasize that grazing in this study includes trampling on the vegetation in its definition.

\section{Selection of Study Sites}

To be able to study a wide array of nutrient availabilities, we selected four topographically defined vegetation types (Giblin and others 1991; Oksanen and Virtanen 1995; Elvebakk 1999) on the lightly grazed side of the fence: (1) exposed ridges (dry heath), (2) higher zonal sites (heath), (3) lower zonal sites (snowbeds) and (4) depressions (willow sites) (Figure 1; see Elvebakk 1999 for a description of topographic gradients in the arctic). These habitat types are expected to differ in soil nutrient availability based on their topographic position, with the lowest nutrient availabilities in the ridges and the highest in the depressions (Giblin and others 1991). Several other factors of profound importance also change across these topographic gradients. Soil moisture and vegetation height increased from the ridges to the depressions (te Beest and others 2016), the latter being indicative of winter snow depth (McFadden and others 2001). The vegetation composition in the lightly grazed sites varied across this topographic gradient. The exposed ridges were dominated by low evergreen shrubs such as Empetrum hermaphroditum and Vaccinium vitis-idaea. The higher zonal vegetation was dominated by heath vegetation such as Betula nana, Empetrum hermaphroditum and Vaccinium vitis-idaea. These two heath vegetation types are indicative of more nutrient-poor conditions (Björk and others 2007; Sundqvist and others 2011a; Giesler and others 2012). Lower zonal sites were dominated by graminoids Carex bigelowii, Agrostis mertensii and Deschampsia flexuosa together with the forb Bistorta vivipara. Depressions were dominated by the willow shrub Salix glauca and graminoids and forbs such as Carex nigra, Cornus suecica, Equisetum sylvaticum and Viola biflora. The presence of forbs and graminoids in the latter two vegetation types is indicative of more nutrient-rich conditions as compared to the former heath vegetation types (Björk and others 2007; Sundqvist and others 201la; Giesler and others 2012). Vegetation in the heavily grazed sites was dominated by graminoids (for example, Festuca ovina, Poa alpina, several Carex species) and forbs (for example, Bistorta vivipara, Viola biflora) at all topographic positions (see Figure 1 for photographs of the vegetation at each topographic position and Figure 4 for data on composition of plant functional types).

We chose four replicates sites for each vegetation type. We randomly selected $1 \mathrm{~m} \times 1 \mathrm{~m}$ plots on both sides of the fence ( 32 plots in total) within those sites that were paired as topographically and edaphically uniform as we could. The distance between pairs was approximately $10 \mathrm{~m}$, so that differences in soil and vegetation within a set of paired plots could be assumed to result from reindeer grazing, not environmental variation. Sets of paired plots were spaced approximately $100 \mathrm{~m}$ apart along the fence line, resulting in a total distance between first and last plots of approximately $2 \mathrm{~km}$. We consider this sufficient to ensure adequate independence among them (Sundqvist and others $2011 b)$.

\section{Soil Sampling and Measurements}

In 2013, we collected soil samples from the whole organic layer at three occasions: in early June, late July and mid-September. The sampling was performed using a soil corer ( $7 \mathrm{~cm}$ diameter), and one to two cores were taken at one corner of each plot. If two cores were collected, they were pooled into one composite sample. The samples were frozen for two to five months depending on sampling time until analysis. Live plant material and roots were removed, and the samples were homogenized after thawing. Bulk density, soil moisture $\left(105^{\circ} \mathrm{C}, 12 \mathrm{~h}\right)$ and loss on ignition $\left(475^{\circ} \mathrm{C}, 4 \mathrm{~h}\right)$ were determined on all soil samples. For the soil sampled in July, total $\mathrm{C}$ and $\mathrm{N}$ concentrations were analyzed by an automated analyzer (Costech ECS 4010, Costech International S.p.A., Italy). For all soil samples, a sub-sample of $2 \mathrm{~g}$ fresh weight was extracted with $50 \mathrm{ml}$ of $0.5 \mathrm{M} \mathrm{K}_{2} \mathrm{SO}_{4}$ on a shaker (1 h) and filtered, and extractable inorganic $\mathrm{N}$ and $\mathrm{P}$ concentrations (i.e., $\mathrm{NO}_{3}-\mathrm{N}, \quad \mathrm{NH}_{4}-\mathrm{N}, \quad \mathrm{PO}_{4}-\mathrm{P}$ ) were determined on the filtrate colorimetrically (Bremner 1965) by an automated flow injection analyzer (FIA star 5000, FOSS Analytical, Denmark). Total extractable $\mathrm{N}$ and $\mathrm{P}$ concentrations were analyzed in the extracts by oxidizing all extractable $\mathrm{N}$ and $\mathrm{P}$ to $\mathrm{NO}_{3}$ and $\mathrm{PO}_{4}$ (Williams and others 1995) and then analyzing them colorimetrically as above. Microbial biomass $\mathrm{N}$ and $\mathrm{P}$ were extracted from soils using $0.5 \mathrm{M} \mathrm{K}_{2} \mathrm{SO}_{4}$ after chloroform fumiga- 


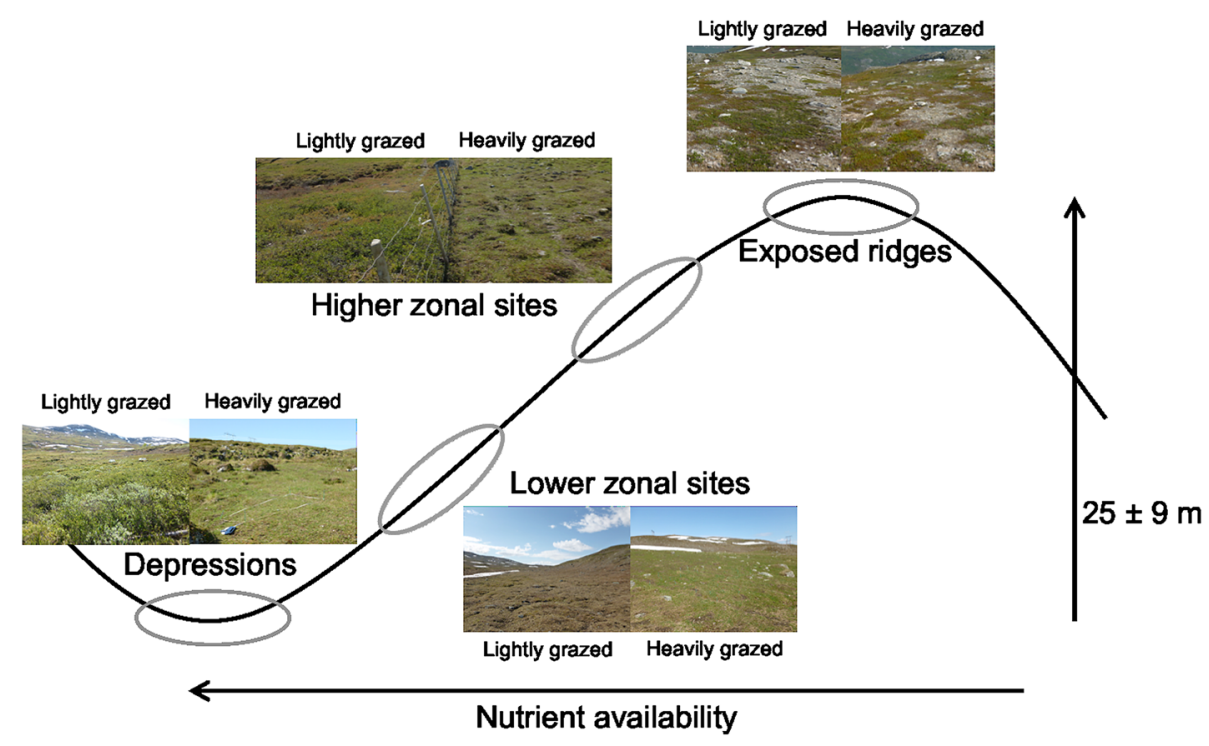

Figure 1. Schematic of the topographic gradient showing the four positions at which study sites were selected including photographs of the vegetation on the lightly grazed and heavily grazed side of the reindeer fence. This topographic gradient is assumed to represent a decreasing gradient in nutrient availability from depressions to exposed ridges. Mean elevation \pm SE between depressions and exposed ridges is shown. tion (18 h; Brookes and others 1985) and analyzed as total extractable $\mathrm{N}$ and $\mathrm{P}$ after oxidation as described above. Microbial $\mathrm{N}$ and $\mathrm{P}$ were calculated by subtracting total extractable $\mathrm{N}$ or $\mathrm{P}$ concentrations in the unfumigated extracts from those in the fumigated ones. Extractable inorganic $\mathrm{N}$ and $\mathrm{P}$ pools in each plot were determined from soil bulk density values and organic layer depth.

We furthermore used the buried bag method for determination of net $\mathrm{N}$ and $\mathrm{P}$ mineralization rates (Eno 1960). For this, we collected the top $5 \mathrm{~cm}$ of the organic layer (soil corer diameter $7 \mathrm{~cm}$ ) at each plot in early June 2013, which roughly equaled the mean depth of the organic layer $(4.1 \pm 0.3 \mathrm{~cm}$ for the lightly grazed and $4.9 \pm 0.5 \mathrm{~cm}$ for the heavily grazed plots, mean $\pm \mathrm{SE}$ ). The samples were put into a polyethylene bag after removal of aboveground plant material. The polyethylene bags were then reburied and covered with the removed plant material and a thin layer of moss. Bags were collected after 47-50 days (late July) and were kept frozen for 4 months until analysis. We analyzed the soil incubations for extractable $\mathrm{N}$ and $\mathrm{P}$ concentrations using the same methods as described above. Net mineralization rates per day were calculated as the change in extractable $\mathrm{N}$ or $\mathrm{P}$ concentrations from the retrieved soil incubations and the 'initial' soil cores taken early June 2013 divided by the amount of days they were incubated in the field.

\section{Vegetation Sampling and Measurements}

We estimated relative abundance and species composition of plants in all plots at the peak of the growing season (31 July-1 August 2013) with a modified point intercept method: 100 pins per
$1 \mathrm{~m} \times 1 \mathrm{~m}$ plot. This index correlates well with plant biomass for a single species (Jonasson 1988). Additionally, we harvested aboveground plant biomass in a $25 \mathrm{~cm} \times 25 \mathrm{~cm}$ square adjacent to each plot. The harvested material was visually sorted to the level of plant functional type (that is, evergreen shrub, deciduous shrub, forb and graminoid), dried $\left(60^{\circ} \mathrm{C}, 48 \mathrm{~h}\right)$ and ground in a ball mill. Samples were analyzed for total $\mathrm{C}$ and $\mathrm{N}$ concentrations (Costech ECS 4010, Costech International S.p.A., Italy). Total P concentrations in the plant samples were determined using the ignition method described by Andersen (1976) after which molybdate reactive phosphate was determined spectrophotometrically (PerkinElmer Lambda 40 UV/VIS Spectrometer, PerkinElmer, USA) as described by Murphy and Riley (1962).

We additionally collected soil turfs (ca. $30 \mathrm{~cm} \times 20 \mathrm{~cm}$ ), consisting of the ground vegetation and the top organic layer, at a corner of each plot in the middle of September 2013. Because most of the plant leaves had senesced, the collected litter represented current year litter combined with the surface leaf litter stock that has senesced in recent years but not yet fully decomposed (Buckeridge and others 2010). The turfs were frozen until analysis. After thawing, a sample square $\left(193 \pm 5 \mathrm{~cm}^{2}\right)$ on each turf was selected in which all live plant material was removed and the remaining surface litter collected by hand and visually sorted to the level of plant functional type (that is, evergreen shrub, deciduous shrub, forb and graminoid). All litter was dried $\left(60^{\circ} \mathrm{C}, 48 \mathrm{~h}\right)$ and weighed to determine total litter biomass per plot. The dried material was then ground and analyzed for total $\mathrm{C}, \mathrm{N}$ and $\mathrm{P}$ concentrations as described above. 

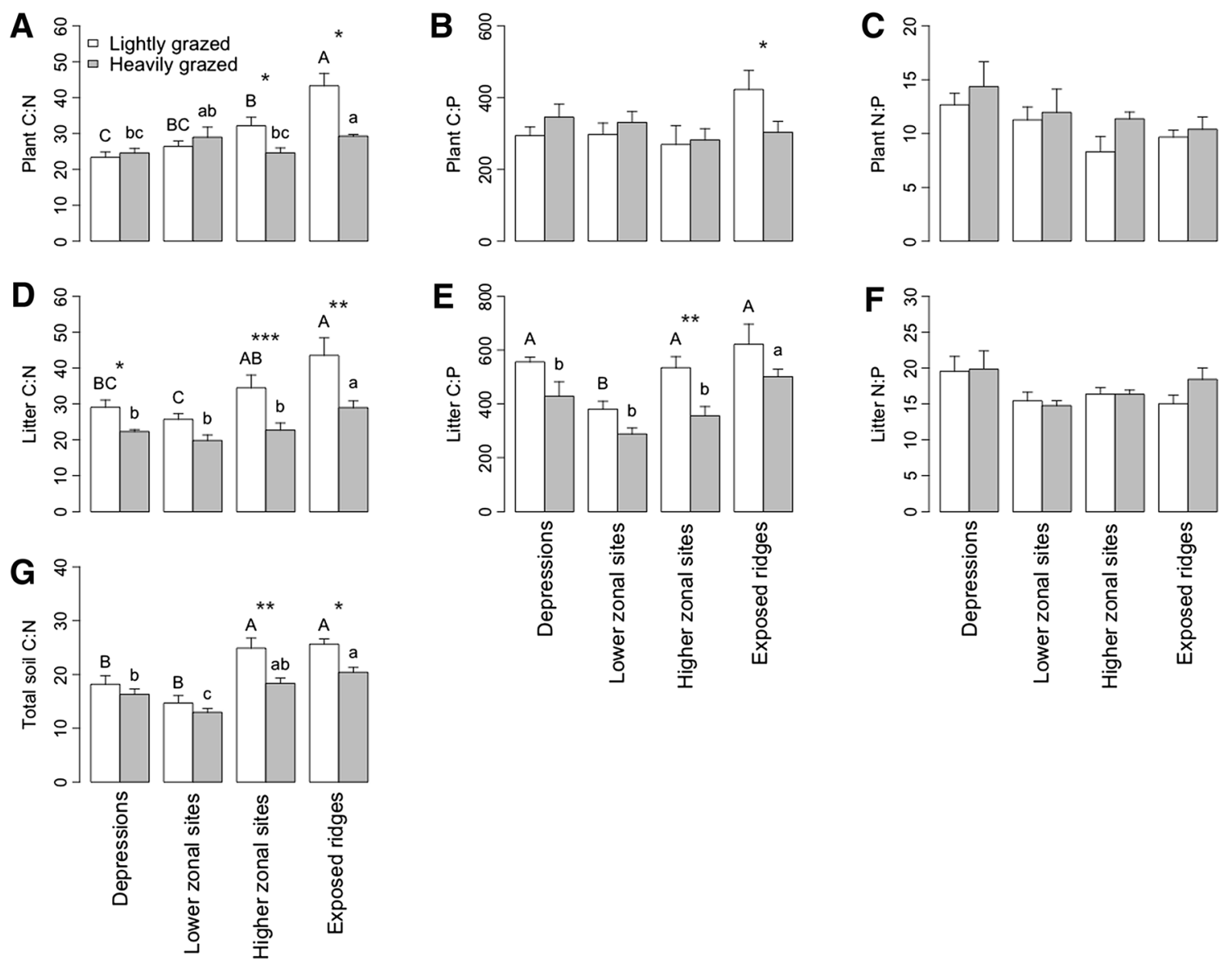

Figure 2. Plant $(\mathbf{A}-\mathbf{C})$ and litter $\mathrm{C} / \mathrm{N} / \mathrm{P}$ ratios $(\mathbf{D}-\mathbf{F})$ and total soil $\mathrm{C} / \mathrm{N}$ ratios $(\mathbf{G})$ in sites located at different topographic positions on the lightly grazed (white bars) or heavily grazed (gray bars) side of the reindeer fence. Bars show mean values per topographic position and grazing regime $( \pm \mathrm{SE} ; n=4)$. Bars within a grazing regime not connected by the same letter indicate significant differences between topographic positions; uppercase letters are for lightly grazed plots, lowercase letters for heavily grazed plots. Asterisks indicate significant differences in $\mathrm{C} / \mathrm{N}$ ratios between grazing regimes for a certain topographic position with $* P<0.05,{ }^{* *} P<0.01$ or $* * * P<0.001$. No letters or asterisks indicate no significant differences between topographic positions and grazing regime.

We calculated community-weighted mean values for plant and litter $\mathrm{C} / \mathrm{N}, \mathrm{C} / \mathrm{P}$ and $\mathrm{N} / \mathrm{P}$ ratios in each plot by multiplying elemental ratios of each plant functional group (that is, evergreen shrub, deciduous shrub, graminoid and forb) by relative abundance or litter biomass of this functional group, adding these values and then dividing them by the total plant abundance or litter biomass in each plot.

\section{Statistical Analyses}

Results on soil extractable $\mathrm{N}$ and $\mathrm{P}$, microbial $\mathrm{N}$ and $\mathrm{P}$, and net $\mathrm{N}$ and $\mathrm{P}$ mineralization rates were calculated both per soil area and soil OM. Additionally, we used the mean values for extractable and microbial $\mathrm{N}$ and $\mathrm{P}$ across the three collection dates to minimize the variation throughout the growing season. We removed one data point from the statistical analyses (a lightly grazed plot at the topographic position of depression for the sampling month June), as it was not possible for us to determine the thickness of the organic layer in this plot due to waterlogging, and we therefore could not accurately estimate soil nutrient availabilities in this plot.

We analyzed the effects of grazing regime, topographic position and their interaction on plant, litter and soil elemental ratios, soil extractable $\mathrm{N}$ and $\mathrm{P}$, net $\mathrm{N}$ and $\mathrm{P}$ mineralization rates, microbial $\mathrm{N}$ and $\mathrm{P}$ with linear-mixed effects models, whereby we used the paired plot number as random factor to account for the spatial autocorrelation of the paired study design. To test for the effect of reindeer on the relative abundance of plant functional types (that is, evergreen shrub, deciduous shrub, forb 

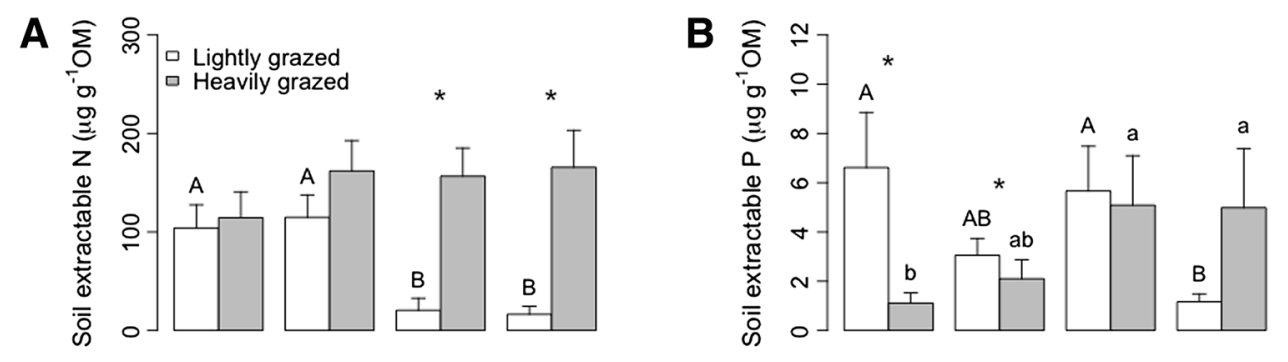

Figure 3. Soil extractable $\mathrm{N}(\mathbf{A})$ and $\mathrm{P}$ (B), net $\mathrm{N}(\mathbf{C})$ and $\mathrm{P}$ mineralization rates $(\mathbf{D})$, and microbial $\mathrm{N}(\mathbf{E})$ and $\mathrm{P}$ biomass $(\mathbf{F})$ per soil OM in sites located at different topographic positions on the lightly grazed (white bars) or heavily grazed
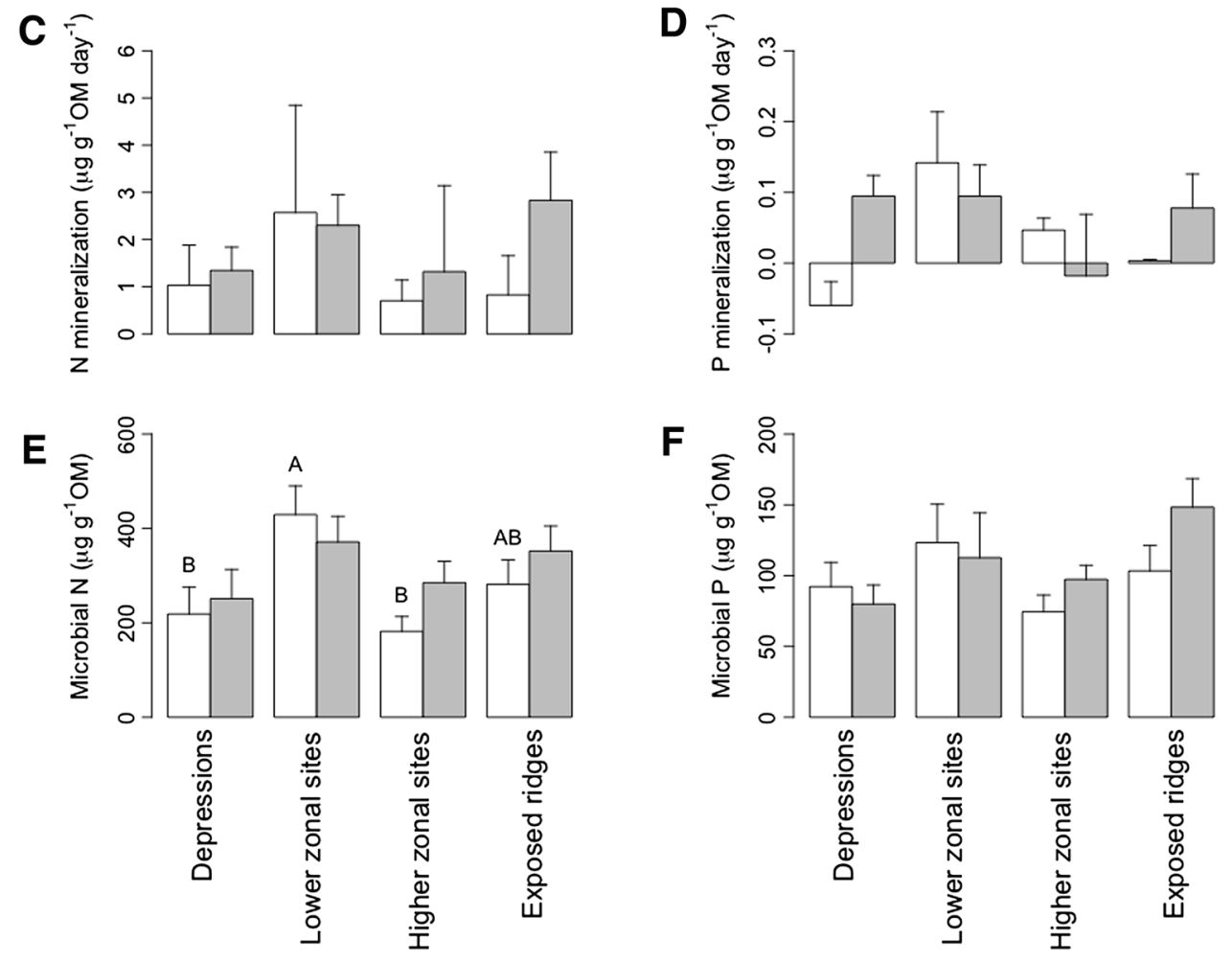
(gray bars) side of the reindeer fence. Bars show mean values per topographic position and grazing regime $( \pm \mathrm{SE}$; $n=4)$. Bars within a grazing regime not connected by the same letter indicate significant differences between topographic positions; uppercase letters are for lightly grazed plots, lowercase letters for heavily grazed plots. Asterisks indicate significant differences in $\mathrm{C} / \mathrm{N}$ ratios between grazing regimes for a certain topographic position with $* P<0.05$. No letters or asterisks indicate no significant differences between topographic positions and grazing regime.

Table 1. ANOVA Results for the Effects of Grazing Regime, Topographic Position and Their Interaction on Several Plant and Soil Elemental Ratios

\begin{tabular}{|c|c|c|c|c|c|c|}
\hline \multirow{2}{*}{$\begin{array}{l}\text { Plant and soil } \\
\text { elemental ratios }\end{array}$} & \multicolumn{2}{|c|}{ Grazing regime } & \multicolumn{2}{|c|}{ Topographic position } & \multicolumn{2}{|c|}{$\mathrm{GR} \times \mathrm{TP}$} \\
\hline & $F$ & $P$ & $F$ & $P$ & $F$ & $P$ \\
\hline Mean plant $\mathrm{C} / \mathrm{N}$ & 12.6 & 0.004 & 9.5 & 0.002 & 10.3 & 0.001 \\
\hline Mean plant C/P & 0.02 & 0.884 & 1.2 & 0.356 & 4.1 & 0.032 \\
\hline Mean plant N/P & 5.9 & 0.032 & 2.0 & 0.167 & 1.7 & 0.218 \\
\hline Mean litter $\mathrm{C} / \mathrm{N}$ & 71.5 & $<0.001$ & 8.5 & 0.003 & 1.1 & 0.370 \\
\hline Mean litter C/P & 31.6 & $<\mathbf{0 . 0 0 1}$ & 10.4 & 0.001 & 0.7 & 0.562 \\
\hline Mean litter N/P & 0.8 & 0.378 & 2.5 & 0.114 & 1.3 & 0.322 \\
\hline Total soil $\mathrm{C} / \mathrm{N}$ & 69.7 & $<0.001$ & 13.4 & $<0.001$ & 4.5 & 0.024 \\
\hline
\end{tabular}


Table 2. ANOVA Results for the Effects of Grazing Regime, Topographic Position and Their Interaction on Several Measures of Soil $\mathrm{N}$ and $\mathrm{P}$

\begin{tabular}{|c|c|c|c|c|c|c|}
\hline \multirow[t]{2}{*}{ Soil variables } & \multicolumn{2}{|c|}{ Grazing regime } & \multicolumn{2}{|c|}{ Topographic position } & \multicolumn{2}{|c|}{$\mathrm{GR} \times \mathrm{TP}$} \\
\hline & $F$ & $P$ & $F$ & $P$ & $F$ & $P$ \\
\hline \multicolumn{7}{|l|}{ Extractable soil N } \\
\hline$\left(\mu \mathrm{g} \mathrm{OM}^{-1}\right)$ & 40.3 & $<0.001$ & $\begin{array}{l}0.1 \\
5.4\end{array}$ & $\begin{array}{l}0.003 \\
0.006\end{array}$ & $\begin{array}{l}0.0 \\
8.0\end{array}$ & $\begin{array}{l}.003 \\
0.007\end{array}$ \\
\hline \multicolumn{7}{|l|}{$\mathrm{N}$ mineralization } \\
\hline$\left(\mathrm{mg} \mathrm{m}^{-2} \mathrm{day}^{-1}\right)$ & 3.3 & 0.082 & 1.0 & 0.400 & 0.1 & 0.951 \\
\hline$\left(\mu \mathrm{g} \mathrm{g} \mathrm{OM}^{-1} \mathrm{day}^{-1}\right)$ & 1.0 & 0.329 & 0.7 & 0.545 & 0.3 & 0.815 \\
\hline \multicolumn{7}{|l|}{ Soil microbial N } \\
\hline$\left(\mathrm{mg} \mathrm{m}^{-2}\right)$ & 0.7 & 0.401 & 3.5 & 0.030 & 0.2 & 0.875 \\
\hline$\left(\mu \mathrm{g} \mathrm{g} \mathrm{OM}{ }^{-1}\right)$ & 1.7 & 0.203 & 4.0 & 0.020 & 0.3 & 0.832 \\
\hline \multicolumn{7}{|l|}{ Extractable soil P } \\
\hline$\left(\mu \mathrm{g} \mathrm{g} \mathrm{OM}{ }^{-1}\right)$ & $\begin{array}{l}1.0 \\
0.8\end{array}$ & 0.374 & $\begin{array}{l}1.2 \\
1.3\end{array}$ & 0.303 & $\begin{array}{l}5.0 \\
5.1\end{array}$ & $\begin{array}{l}0.004 \\
0.007\end{array}$ \\
\hline \multicolumn{7}{|l|}{ P mineralization } \\
\hline$\left(\mathrm{mg} \mathrm{m}^{-2} \mathrm{day}^{-1}\right)$ & 1.7 & 0.206 & 1.4 & 0.287 & 2.5 & 0.089 \\
\hline$\left(\mu \mathrm{g} \mathrm{g} \mathrm{OM}^{-1} \mathrm{day}^{-1}\right)$ & 0.7 & 0.411 & 1.9 & 0.159 & 2.5 & 0.088 \\
\hline \multicolumn{7}{|l|}{ Soil microbial P } \\
\hline$\left(\mathrm{mg} \mathrm{m}^{-2}\right)$ & 0.03 & 0.875 & 1.7 & 0.194 & 0.3 & 0.846 \\
\hline$\left(\mu \mathrm{g} \mathrm{g} \mathrm{OM}^{-1}\right)$ & 0.02 & 0.880 & 1.5 & 0.246 & 0.7 & 0.551 \\
\hline
\end{tabular}

and graminoid) at each topographic position, we also used linear-mixed effect models with plant functional type and grazing regime as fixed effects and paired plot number as random effect. If necessary, data were log-transformed to meet assumptions of normality and homogeneity of variance. All data analyses were performed with the open source R, version 3.0.1 (R Development Core Team 2013).

\section{RESUlTS}

The topographic gradient from exposed ridges to depressions represented a gradient in nutrient availability, as indicated by decreasing $\mathrm{C} / \mathrm{N}$ ratios in plant, litter and soil (Table 1; Figure 2A, B, G) and increasing extractable $\mathrm{N}$ (Figure $3 \mathrm{~A}$ ) in the soil. Reindeer significantly decreased plant, litter and soil $\mathrm{C} / \mathrm{N}$ ratios, especially at the inherently nutrient-poor exposed ridges and higher zonal sites, whereas the only effect in the nutrient-rich depressions or lower zonal sites was the decrease in litter C/N (Table 1; Figure 2A, D, G). There was no uniform effect of reindeer on plant $\mathrm{C} / \mathrm{P}$ ratios, although there was a significant decrease in the exposed ridges. Litter $\mathrm{C} / \mathrm{P}$ ratios decreased only in the higher zonal sites, but tended to decrease when reindeer were present at the other topographic positions (Table 1; Figure 2B, E). Reindeer had no effect on plant or litter N/P ratios (Table 1; Figure $2 \mathrm{C}, \mathrm{F}$ ).

Reindeer increased soil extractable $\mathrm{N}$ in the more nutrient-poor environments, for example, the higher zonal sites and exposed ridges, but did not significantly change $\mathrm{N}$ in the more nutrient-rich depressions and lower zonal sites (Table 2; Figure $3 \mathrm{~A})$. The impact of reindeer on soil extractable $\mathrm{P}$ showed the opposite pattern: a decrease in the depressions and lower zonal sites and no significant change in higher zonal sites and exposed ridges (Table 2; Figure 3B).

The in situ incubations did not reveal any statistically significant differences in net $\mathrm{N}$ or $\mathrm{P}$ mineralization rates between the grazing regimes (Table 2; Figure 3C, D). There was a trend toward higher net $\mathrm{N}$ mineralization rates in the heavily grazed sites, but only when calculated per area (Table 2). Soil microbial $\mathrm{N}$ was higher in the lower zonal sites than in the depressions and higher zonal sites when lightly grazed, but reindeer had no statistically significant effects on soil microbial $\mathrm{N}$ or $\mathrm{P}$ (Table 2; Figure 3E, F). 
At all topographic positions the plant community composition differed between grazing regimes (Figure 4). The shrubby vegetation that dominated the depressions, higher zonal sites and exposed ridges in the lightly grazed area was replaced by graminoid-dominated vegetation in the heavily grazed area. In contrast, the lower zonal sites were dominated by graminoids regardless of grazing pressure.

\section{Discussion}

The effects of reindeer on $\mathrm{N}$ availability were partly in accordance with our hypotheses in that we found clear responses to reindeer in both soil and plant traits in the more nutrient-poor environments, with decreases in $\mathrm{C} / \mathrm{N}$ ratio and increases in soil extractable $\mathrm{N}$ in the exposed ridges and higher zonal sites (Figures 2, 3; Table 3). These results are in agreement with the negative relationship between plant $\mathrm{N}$ concentration and the effect of herbivores on nutrient availability found in a recent meta-analysis (Bakker and others 2009) as well as the predictions of a recent model analysis (Cherif and Loreau 2013). However, they contrast from the general concensus that herbivores have mainly positive effects on nutrient availability and primary production in nutrient-rich environments dominated by plants of high quality and mainly negative ones in nutrient-poor environments dominated by plants of low quality (Hobbs 1996; Bardgett and Wardle 2003; Pastor and others
2006). This shows that there is need for a new conceptual understanding of the mechanisms driving the effect of herbivores on nutrient availabilities (Schrama and others 2013; Sitters and Olde Venterink 2015).

Herbivores favored and facilitated the growth of grazing tolerant rather than resistant plants independent of the habitat fertility in our study system, in contrast with what has been previously assumed (Bardgett and Wardle 2003; Wardle and others 2004; Pastor and others 2006). This is not too surprising since many other factors in addition to the fertility of a site have been found to influence whether herbivores favor grazing resistant or tolerant plants. Although selective herbivory often reduces the abundance of plants with the highest nutrient content, herbivores can also favor nutrient-rich plants with fast decomposing litter and thus increase nutrient cycling (Belovsky and Slade 2000). This seems to be especially common in systems where the level of herbivory is high (Dahlgren and others 2009), selectivity is low (Pastor and others 2006), differences in plant regrowth rates are larger than differences in palatability (Olofsson and others 2012), or where the non-selective physical disturbance from trampling is high (Olofsson and Oksanen 2002; Olofsson and others 2004). At least the first and the last of these factors are true in our study system, since the density of reindeer is high in the heavily grazed sites, and reindeer move and trample on the vegetation more than many other herbivores. However, it should be

Table 3. Summary of the Effects of Reindeer on Soil, Plant and Litter C/N/P Ratios and Soil Extractable N and P Concentrations at the Four Topographic Positions

\begin{tabular}{lllll}
\hline & Depressions & Lower zonal sites & Higher zonal sites & Exposed ridges \\
\hline Soil C/N & & & $\downarrow$ & $\downarrow$ \\
Soil extractable N & & $\uparrow$ & $\uparrow$ & \\
Soil extractable P & $\downarrow$ & $\downarrow$ & $\uparrow$ & $\uparrow$ \\
Soil extractable N/P & $\uparrow$ & & $\downarrow$ & $\downarrow$ \\
Plant C/N & & & $\downarrow$ \\
Plant C/P & & & \\
Plant N/P & & & $\downarrow$ \\
Litter C/N & $\downarrow$ & $\downarrow$ & \\
Litter C/P & & & \\
Litter N/P & & & \\
& & & \\
Dominating plant type & Deciduous & Graminoids & Deciduous & \\
& $\downarrow$ & $\downarrow$ & $\downarrow$ & Evergreen \\
& Graminoids & Graminoids & Graminoids & Graminoids
\end{tabular}

Downward arrows indicate a significant decrease due to reindeer and upward arrows a significant increase. The last row of the table shows the shift in dominating plant type due to reindeer from lightly grazed sites toward heavily grazed sites (indicated by the arrow). 


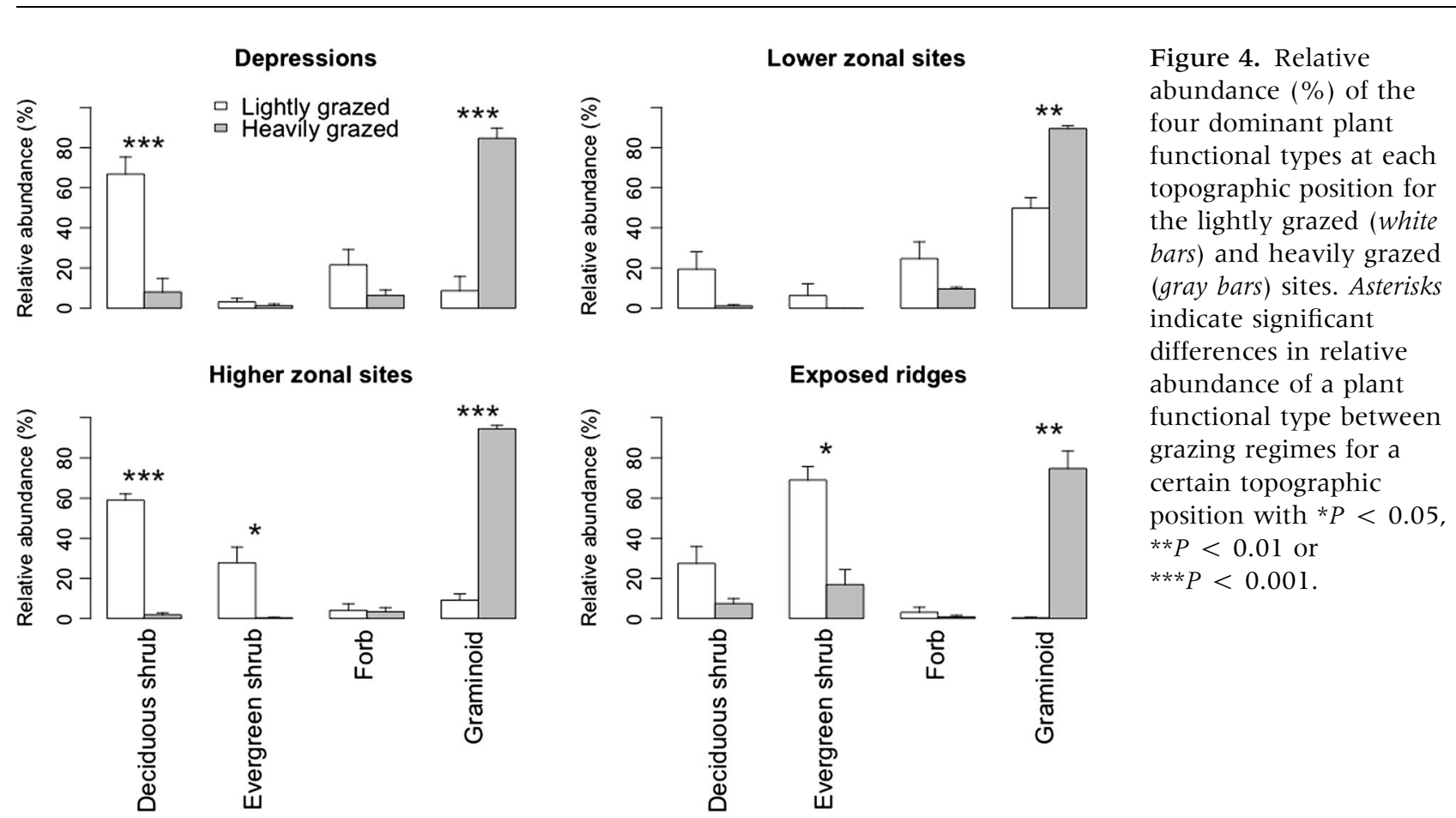

noted that our data indicate that the behavior of reindeer close to the fence does not differ from reindeer in places without fences, as the ratio of trampling to dung is close to the Scandinavian average (Olofsson and others, unpublished data).

The effect of reindeer on $\mathrm{N}$ availability seems to be closely linked to the effect of reindeer on $\mathrm{C} / \mathrm{N}$ ratios of plants and litter, since $\mathrm{N}$ availability increased in the two nutrient-poor sites, where $\mathrm{C} / \mathrm{N}$ ratios of plants and litter decreased (Table 3). Graminoids have become dominant in the heavily grazed areas irrespectively of the plant community composition in lightly grazed conditions (Figure 4; Table 3). This vegetation shift was most likely caused by an increased $\mathrm{N}$ availability and a competitive advantage for the graminoids. This resulted in a reduced $\mathrm{C} / \mathrm{N}$ ratio of the litter in the more shrubby habitats where the vegetation shifted from being dominated by deciduous $(\mathrm{C} / \mathrm{N}=31.9)$ and evergreen shrubs $(\mathrm{C} / \mathrm{N}=38.7)$ to graminoids $(\mathrm{C} /$ $\mathrm{N}=24.4$ ). Moreover, the increased soil $\mathrm{N}$ availability and decreased plant $\mathrm{C} / \mathrm{N}$ ratios are also expected to result in faster decomposing litter (Olofsson and Oksanen 2002; Sundqvist and others 201 la) that can maintain a higher $\mathrm{N}$ cycling and a continued dominance of the graminoids. In the habitat already dominated by graminoids in lightly grazed conditions, the $\mathrm{C} / \mathrm{N}$ ratio of the litter did not change (Figure 2D; Table 3) suggesting that the effect of reindeer grazing on $\mathrm{N}$ availability is marginal here. Although the causality cannot be determined with the study design applied here, the most parsimonious interpretation of these results is that plant community shifts to graminoids favor a higher $\mathrm{N}$ cycling. The microbial $\mathrm{N}$ pool was highest in the lower zonal sites, where both extractable $\mathrm{N}$ and $\mathrm{N}$ mineralization were also highest, and litter and soil C/N lowest (Figures 2D, G, 3). This relationship, however, might not be causal but rather driven by some other aspect of the topographic gradient since microbial $\mathrm{N}$ was not influenced by reindeer and the associated changes in soil and litter $\mathrm{C} / \mathrm{N}$ ratios (Figure 3E; Table 2). Microbial $\mathrm{P}$ pools were in contrast not influenced by topography or reindeer grazing (Figure 3F; Table 2). To what extent these changes will also change other soil traits related to nutrient availability and how persistent these changes are without the influence of reindeer grazing remains to be addressed in future studies.

The higher $\mathrm{N}$ availability in the nutrient-poor sites could potentially be the result of a higher $\mathrm{N}$ mineralization rate in response to a lower $\mathrm{C}$ supply to the decomposer community in the heavily grazed sites as suggested by Cherif and Loreau (2013); the effect of reindeer on $\mathrm{N}$ mineralization mimicked their effect on $\mathrm{N}$ availability in the nutrient-poor sites albeit the effects on $\mathrm{N}$ mineralization were not statistically significant (Figure 3C). Thus, at this stage, the hypothesis stands neither confirmed nor refuted. However, the concomitant decline in soil and litter $\mathrm{C} / \mathrm{N}$ ratios (major drivers of $\mathrm{N}$ mineralization; Manzoni and Porporato 2009), increase in $\mathrm{N}$ mineralization rate, and in- 
crease in $\mathrm{N}$ availability due to grazing in nutrientpoor sites advocate for further enquiries in this hypothesis in the tundra ecosystem.

The topographic gradient used here was indeed a strong gradient in nutrient availability and vegetation composition as expected. It is also expected to be a strong gradient in other environmental factors such as soil $\mathrm{pH}$, soil moisture, vegetation height and snow cover (Giblin and others 1991; Oksanen and Virtanen 1995; Elvebakk 1999; Björk and others 2007), which is also true for our sites (see material and methods section for details). We would like to stress that the type of topographic fertility gradient we used has been described in tundra ecosystems in detail over the past three decades and consistently shows strong linkages with factors, such as soil $\mathrm{pH}$, soil $\mathrm{C} / \mathrm{N}$ ratio and plant nutrient availability (Giblin and others 1991, and more recent papers such as Sundqvist and others 2014 and De Long and others 2016). Moreover, all of these factors also differed between grazing regimes. However, we do not see how any of these factors could explain the increase in soil extractable $\mathrm{N}$ and the decreased $\mathrm{C} / \mathrm{N}$ ratios in soils, litter and plants in the nutrient-poor habitats.

The extractable P in the soil was lower in heavily grazed sites in the two nutrient-rich habitats (Figure 3B; Table 3). This combined with the higher extractable $\mathrm{N}$ in the nutrient-poor habitats resulted in a higher extractable N/P ratio in heavily grazed sites in all habitats (with a trend for lower zonal sites at $P=0.1$; Table 3; Appendix B). The lower soil $\mathrm{P}$ availability and higher N/P ratio suggest that large ungulates could drive the vegetation in the direction of P-limitation in accordance with several previous studies (Binkley and others 2003; Anderson and others 2007; Mekuria and others 2007). Because recent studies suggest that P-limitation of plants and microbes in the tundra might be more common than previously assumed (Giesler and others 2012; Zamin and Grogan 2012; Sundqvist and others 2014), the effect of reindeer on $\mathrm{P}$ availability could potentially be important. Although the soil N/P ratios were higher in the heavily grazed sites in the two most nutrient-rich sites, an eventual P-limitation was not well manifested in the vegetation since the only differences were a lower plant $\mathrm{C} / \mathrm{P}$ in the heavily grazed exposed ridges and a lower litter $\mathrm{C} / \mathrm{P}$ ratio in the heavily grazed higher zonal sites (Figure 2B, E; Table 3). This indicates that soil $\mathrm{P}$ availability was not as closely linked to the vegetation as soil $\mathrm{N}$ availability. One explanation for this could be that reindeer simply remove more $\mathrm{P}$ from the system since they have a high $\mathrm{P}$ demand for their antler production (Moen and others 1999). An alternative mechanism could be that the decrease in extractable $\mathrm{P}$ is caused by a change in the soil chemical properties of the humus layer due to trampling. Trampling-induced soil compaction by herbivores (Schrama and others 2013) could potentially result in an increased connectivity with the underlying mineral soil and cause a transfer of $\mathrm{P}$-sorbing elements, such as $\mathrm{Al}$ and $\mathrm{Fe}$, from the mineral soil into the humus layer (Giesler and others 2000). This would increase the P-sorbing capacity of the humus layer and decrease extractable P concentrations. Further studies are, however, needed to unravel the causes behind the lower extractable $\mathrm{P}$ in heavily grazed sites in the nutrient-rich environments.

If nutrient-rich tundra environments are closer to P-limitation than nutrient-poor (as indicated by Sundqvist and others 2011a; Giesler and others 2012), they might be more vulnerable to changes in their P status due to herbivore grazing. Such changes could be related to the shift in plant functional type and thereby nutrient stoichiometry, but also due to changes in soil physical and chemical properties. The humus thickness in more fertile soils tends to be more shallow and moist (Giesler and others 2012), and these soils may thus be more sensitive to trampling compared to sites with nutrient-poor heathland soils with a thicker humus layer. The response to reindeer across a topographic gradient of fertility could thus be an interactive effect of both the prevailing nutrient status before grazing, as we see in this study, and the sensitivity of an environment to physiochemical changes. Because $\mathrm{P}$ is more likely to be affected by the latter, our study emphasizes that it is important in future studies to include both the elements $\mathrm{N}$ and $\mathrm{P}$ and relate their changes due to herbivory to both biotic features and physiochemical properties. The strong effect of reindeer presented here is detected in an area with high reindeer densities, due to the presence of a boundary fence. Understanding the importance of these processes across the whole range of reindeer densities found in the arctic tundra is an important challenge in the future.

\section{ACKNOWLEDGEMENTS}

We thank Jonas Gustafsson, Maria Noro-Larsson and Ruth de Groot for their assistance in the field and laboratory. Sari Stark, Sirkka Aakonen, Anders Jonsson, Jan Johansson and Carin Olofsson are acknowledged for their help with the chemical analyses. We thank Harry Olde Venterink, Richard 
Bardgett and two anonymous reviewers for comments on an earlier version of this manuscript. This study was financed by Kempestiftelserna, Formas 2012-1039, 2012-230 and 2015-109, and Gunnar och Ruth Björkmans fund. JS was financially supported by a grant of the Research Foundation Flanders (FWO).

\section{OPEN ACCESS}

This article is distributed under the terms of the Creative Commons Attribution 4.0 International License (http://creativecommons.org/licenses/by/ 4.0/), which permits unrestricted use, distribution, and reproduction in any medium, provided you give appropriate credit to the original author(s) and the source, provide a link to the Creative Commons license, and indicate if changes were made.

\section{REFERENCES}

Aerts R, Chapin FSIII. 2000. The mineral nutrition of wild plants revisited: a re-evaluation of processes and patterns. In: Fitter AH, Raffaelli DG, Eds. Advances in ecological research. San Diego: Academic Press. p 1-67.

Andersen JM. 1976. Ignition method for determination of total phosphorus in lake sediments. Water Res 10:329-31.

Anderson TM, Ritchie ME, McNaughton SJ. 2007. Rainfall and soils modify plant community response to grazing in Serengeti National Park. Ecology 88:1191-201.

Bakker ES, Knops JMH, Milchunas DG, Ritchie ME, Olff H. 2009. Cross-site comparison of herbivore impact on nitrogen availability in grasslands: the role of plant nitrogen concentration. Oikos 118:1613-22.

Bardgett RD, Wardle DA. 2003. Herbivore-mediated linkages between aboveground and belowground communities. Ecology 84:2258-68.

Belovsky GE, Slade JB. 2000. Insect herbivory accelerates nutrient cycling and increases plant production. Proc Natl Acad Sci USA 97:14412-17.

Binkley D, Singer F, Kaye M, Rochelle R. 2003. Influence of elk grazing on soil properties in Rocky Mountain National Park. For Ecol Manag 185:239-47.

Björk RG, Klemedtsson L, Molau U, Harndorf J, Odman A, Giesler R. 2007. Linkages between N turnover and plant community structure in a tundra landscape. Plant Soil 294:247-61.

Bremner JM. 1965. Inorganic forms of nitrogen. In: Black CA, Ed. Methods of soil analysis, part 2. Madison: American Society of Agronomy. p 1179-237.

Brookes P, Kragt JF, Powlson DS, Jenkinson DS. 1985. Chloroform fumigation and the release of soil nitrogen: the effects of fumigation time and temperature. Soil Biol Biohem 17:831-5.

Buckeridge KM, Zufelt E, Chu H, Grogan P. 2010. Soil nitrogen cycling rates in low arctic shrub tundra are enhanced by litter feedbacks. Plant Soil 330:407-21.

Cherif M, Loreau M. 2013. Plant-herbivore-decomposer stoichiometric mismatches and nutrient cycling in ecosystems. Proc Roy Soc B Biol Sci 280:20122453.
Chu H, Grogan P. 2010. Soil microbial biomass, nutrient availability and nitrogen mineralization potential among vegetation-types in a low arctic tundra landscape. Plant Soil 329:411-20.

Dahlgren J, Oksanen L, Oksanen T, Olofsson J, Hamback PA, Lindgren A. 2009. Plant defences to no avail? Responses of plants of varying edibility to food web manipulations in a low arctic scrubland. Evol Ecol Res 11:1189-203.

De Long JR, Sundqvist MK, Gundale MJ, Giesler R, Wardle DA. 2016. Effects of elevation and nitrogen and phosphorus fertilization on plant defence compounds in subarctic tundra heath vegetation. Funct Ecol 30:314-25.

Elvebakk A. 1999. Bioclimatic delimitation and subdivision of the Arctic: Det Norske Videnskaps-Akademi. I. Mat. Naturv. Klasse, Skrifter, Ny serie 38.

Eno C. 1960. Nitrate production in the field by incubating the soil in polyethylene bags. Soil Sci Soc Am J 24:277-9.

Fornara DA, Du Toit JT. 2008. Browsing-induced effects on leaf litter quality and decomposition in a southern African savanna. Ecosystems 11:238-49.

Frank DA, Evans RD. 1997. Effects of native grazers on grassland $\mathrm{N}$ cycling in Yellowstone National Park. Ecology 78:2238-48.

Giblin AE, Nadelhoffer KJ, Shaver GR, Laundre JA, McKerrow AJ. 1991. Biogeochemical diversity along a riverside toposequence in arctic Alaska. Ecol Monogr 61:415-35.

Giesler R, Esberg C, Lagerstrom A, Graae BJ. 2012. Phosphorus availability and microbial respiration across different tundra vegetation types. Biogeochemisrty 108:429-45.

Giesler R, Ilvesniemi H, Nyberg L, van Hees P, Starr M, Bishop K, Kareinen T, Lundstrom US. 2000. Distribution and mobilization of $\mathrm{Al}, \mathrm{Fe}$ and $\mathrm{Si}$ in three podzolic soil profiles in relation to the humus layer. Geoderma 94:249-63.

Hobbs NT. 1996. Modification of ecosystems by ungulates. J Wildl Manag 60:695-713.

Hobbs NT, Schimel DS, Owensby CE, Ojima DS. 1991. Fire and grazing in the tallgrass prairie-contingent effects on nitrogen budgets. Ecology 72:1374-82.

Jonasson S. 1988. Evaluation of the point intercept method for estimation of plant biomass. Oikos 52:101-6.

Manzoni S, Porporato A. 2009. Soil carbon and nitrogen mineralization: theory and models across scales. Soil Biol Biochem 41:1355-79.

McFadden JP, Liston GE, Sturm M, Pielke RA, Chapin FS, III. 2001. Interactions of shrubs and snow in arctic tundra: measurements and models. Soil-vegetation-atmosphere transfer schemes and large-scale hydrological models (Proceedings of a symposium held during the Sixth IAHS Scientific Assembly at Maastricht, The Netherlands, July 2001). IAHS Publ. no. 270, 2001.

McNaughton SJ. 1984. Grazing lawns - animals in herds, plant form, and coevolution. Am Nat 124:863-86.

McNaughton SJ, Banyikwa FF, McNaughton MM. 1997. Promotion of the cycling of diet-enhancing nutrients by African grazers. Science 278:1798-800.

Mekuria W, Veldkamp E, Halle M, Nyssen J, Muys B, Gebrehiwota K. 2007. Effectiveness of exclosures to restore degraded soils as a result of overgrazing in Tigray, Ethiopia. J Arid Environ 69:270-84.

Milchunas DG, Lauenroth WK. 1993. Quantitative effects of grazing on vegetation and soils over a global range of environments. Ecol Monogr 63:327-66. 
Moen RA, Pastor J, Cohen Y. 1999. Antler growth and extinction of Irish elk. Evol Ecol Res 1:235-49.

Murphy J, Riley JP. 1962. A modified single solution method for determination of phosphate in natural waters. Anal Chim Acta 26:31-6.

Oksanen L, Virtanen R. 1995. Topographic, altitudinal and regional patterns in continental and suboceanic heath vegetation of northern Fennoscandia. Acta Bot Fen 153:1-80.

Olofsson J, Kitti H, Rautiainen P, Stark S, Oksanen L. 2001. Effects of summer grazing by reindeer on composition of vegetation, productivity and nitrogen cycling. Ecography 24:13-24.

Olofsson J, Oksanen L. 2002. Role of litter decomposition for the increased primary production in areas heavily grazed by reindeer: a litterbag experiment. Oikos 96:507-15.

Olofsson J, Stark S, Oksanen L. 2004. Reindeer influence on ecosystem processes in the tundra. Oikos 105:386-96.

Olofsson J, Tommervik H, Callaghan TV. 2012. Vole and lemming activity observed from space. Nat Clim Change 2:880-3.

Pastor J, Cohen Y, Hobbs NT. 2006. The role of large herbivores in ecosystem nutrient cycles. In: Dannell R, Bergstrom R, Duncan P, Pastor J, Eds. Large herbivore ecology, ecosystem dynamics and conservation. Cambridge: Cambridge University Press. p 289-319.

Pastor J, Dewey B, Naiman RJ, McInnes PF, Cohen Y. 1993. Moose browsing and soil fertility in the boreal forests of Isle Royale National Park. Ecology 74:467-80.

R Development Core Team. 2013. R: a language and environment for statistical computing. R Foundation for Statistical Computing, Vienna, Austria. http://R-project.org/.

Ritchie ME, Tilman D, Knops JMH. 1998. Herbivore effects on plant and nitrogen dynamics in oak savanna. Ecology 79:16577.

Schrama M, Veen GF, Bakker ES, Ruifrok JL, Bakker JP, Olff H. 2013. An integrated perspective to explain nitrogen mineralization in grazed ecosystems. Perspect Plant Ecol 15:32-44.

Shaver GR, Chapin FS. 1980. Response to fertilization by various plant growth forms in an Alaskan tundra-nutrient accumulation and growth. Ecology 61:662-75.

Sitters J, Olde Venterink H. 2015. The need for a novel integrative theory on feedbacks between herbivores, plants and soil nutrient cycling. Plant Soil 396:421-6.

Stark S, Grellmann D. 2002. Soil microbial responses to herbivory in an arctic tundra heath at two levels of nutrient availability. Ecology 83:2736-44.
Stark S, Mannisto MK, Smolander A. 2010. Multiple effects of reindeer grazing on the soil processes in nutrient-poor northern boreal forests. Soil Biol Biochem 42:2068-77.

Stark S, Strommer R, Tuomi J. 2002. Reindeer grazing and soil microbial processes in two suboceanic and two subcontinental tundra heaths. Oikos 97:69-78.

Stark S, Tuomi J, Strommer R, Helle T. 2003. Non-parallel changes in soil microbial carbon and nitrogen dynamics due to reindeer grazing in northern boreal forests. Ecography 26:51-9.

Sundqvist MK, Giesler R, Graae BJ, Wallander H, Fogelberg E, Wardle DA. 2011 a. Interactive effects of vegetation type and elevation on aboveground and belowground properties in a subarctic tundra. Oikos 120:128-42.

Sundqvist MK, Giesler R, Wardle DA. $2011 \mathrm{~b}$. Within and across species responses of plant traits and litter decomposition to elevation across contrasting vegetation types in subarctic tundra. Plos ONE 6(10):e27056.

Sundqvist MK, Liu ZF, Giesler R, Wardle DA. 2014. Plant and microbial responses to nitrogen and phosphorus addition across an elevational gradient in subarctic tundra. Ecology 95:1819-35.

Tamm CO. 1991. Nitrogen in terrestrial ecosystems: questions of productivity, vegetational changes, and ecosystem stability. In: Billings WD, Colley F, Lange OL, Olson JS, Rammert $\mathrm{H}$, Eds. Ecological studies. New York: Springer.

te Beest M, Sitters J, Ménard CB, Olofsson J. 2016. Reindeer grazing increases summer albedo by reducing shrub abundance in Arctic tundra. Environ Res Lett 1 1:125013.

Van der Wal R, Brooker RW. 2004. Mosses mediate grazer impacts on grass abundance in arctic ecosystems. Funct Ecol 18:77-86.

Wardle DA, Bardgett RD, Klironomos JN, Setala H, van der Putten WH, Wall DH. 2004. Ecological linkages between aboveground and belowground biota. Science 304:1629-33.

Williams BL, Shand CA, Hill M, O'Hara C, Smith S, Young ME. 1995. A procedure for the simultaneous oxidation of total soluble nitrogen and phosphorus in extracts of fresh and fumigated soils and litters. Commun Soil Sci Plan 26:91-106.

Wilsey BJ, Coleman JS, McNaughton SJ. 1997. Effects of elevated $\mathrm{CO} 2$ and defoliation on grasses: a comparative ecosystem approach. Ecol Appl 7:844-53.

Zamin TJ, Grogan P. 2012. Birch shrub growth in the low Arctic: the relative importance of experimental warming, enhanced nutrient availability, snow depth and caribou exclusion. Environ Res Lett 7:034027. 